\title{
Teachers becoming lay practitioners of school community psychology
}

\author{
Ronél Ferreira, Liesel Ebersöhn and Viona Odendaal \\ University of Pretoria
}

\begin{abstract}
This article reports on a study that explored how a community-based intervention with ten teachers could enhance their knowledge and skills related to supporting community members coping with HIV/ AIDS. We conducted a case study using participatory action research methods. Individual interviews, observation, field notes, visual data and reflective journals were utilised as data sources. We found that the participating teachers displayed a willingness to support their community in coping with HIVIAIDS, yet did not perceive themselves as being adequately equipped to do so, and therefore refrained from acting intuitively. The intervention did, however, show signs of an emergent sense of 'becoming' lay practitioners in the face of the social upheaval brought on by the pandemic.
\end{abstract}

Key words: Asset-based intervention, HIV/AIDS, intuitive practice, school community

\section{Introduction}

The vast upheaval in many school communities in the face of HIV/AIDS requires measures that one can almost associate with what happens in natural disasters (for instance, the earthquake in China in 2009) or with the social strain taken by inhabitants of refugee camps. Yet, in South Africa, society has become so used to the presence of HIV/AIDS that it has almost been abstracted in public discourse. Activists campaign relentlessly to keep sufferers in the mind's eye of the public, to make sure that consistent action is taken by those in power. That is why we argue for consistent community-based interventions, however small the scale may be. Schools seem to be slowly regaining their place as community spaces, therefore it makes sense to develop mental hygiene practices through schools. This is also why the notion of a specific brand of community psychology, which centres schools as action hubs, is important. We thus couch this article in what Krige, Pillay and Henning (2010) argue for - the establishment of the notion of school community psychology (the lay practice of members of school communities) in the discourse. With that we also argue for what the cultural theorist, Turner (1982), refers to as a togetherness in 'communitas' (see also Van Heerden 2009), in the face of extreme social upheaval.

Ideally, responses to people's needs for assistance in maintaining mental health at community level (Gow \& Desmond 2002) should be visible across an array of social sectors. Thus, too, the education sector is expected to fulfil a leading role. In reaction to the pandemic, already 14 years ago, the then Minister of Education, Kader Asmal, issued a National Policy on HIV\&AIDS in the National Education Policy Act of 1996, saying that every school needs to develop and implement an HIV/AIDS plan (Department of Education 1999). Asmal provided the following motivation for this policy: 'The school has a responsibility to become a centre of information and support on HIV\&AIDS in the community it serves' (Department of Education 2000:14). We would argue that community psychology needs to establish itself in a specific way as school community psychology practice, in order to train lay practitioners in schools, first and foremost, to provide counselling and support for children and youths affected and infected by HIV/AIDS.

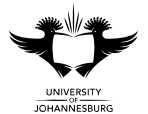


Peltzer (2003) also emphasises the role the education sector can play in communities. The current authors argue that the levels of stigma associated with the pandemic may be reduced if teacher training were more extensive in terms of HIV/AIDS-related issues. This is because teachers have a responsible role and status in their school communities.

This article reports on a study that involved ten teachers in an informal settlement community in the Eastern Cape Province of South Africa, who became involved in community-based initiatives aimed at supporting their school. The study formed part of an ongoing broader research project that commenced in 2003 (Ferreira 2006). During the initial stages of this project, the teachers voiced their concern that they did not have the necessary knowledge and skills to effectively support community members coping with HIV/AIDS, despite their intention and willingness to do so. They were often hesitant in their assistance due to their own perceived lack of competence. In an attempt to address this, and in line with the underlying framework of the broader research project, we conducted a study that focused on the manner in which an asset-based intervention could be utilised to help teachers develop coping and support competencies.

\section{Coping with HIV/AIDS at community level}

The impact of the HIV/AIDS pandemic is complex and potentially devastating for families and communities in different parts of the globe. The African continent is the most affected region in the world, with 70 per cent of the global total of HIV-positive people located in sub-Saharan Africa (Connolly, Colvin, Shisana \& Stoker 2004; Mugabe, Stirling \& Whiteside 2002; Townsend \& Dawes 2004; UNAIDS 2002). South Africa has one of the fastest-growing rates of HIV infection. It is estimated that 13 per cent of South African children between the ages of two and 14 have already lost their mothers, or fathers, or both parents, while 25 per cent of South African children aged 15-18 have lost at least one caregiver or parent. It is further predicted that these statistics will peak in 2015, when three million South African children will have lost their mothers, and a total of 5.7 million one or both parents (Brookes, Shisana \& Richter 2004; Marais 2005).

It is widely documented (see, for example, Lucas 2004; Mallmann 2002; Van Dyk 2001) that communities have to take control of their own wellbeing as social agents, but in the face of huge structural inequalities, the tension between agency and structure is often insurmountable (see Nel, Lazarus \& Daniels 2010). Yet it is the contextual experiences that may, at the same time, determine ways of achieving positive changes in mental healthcare, especially if it could be guided by schools. We use the term 'context' as authors of community psychology use it, and as explored by Lazarus et al. (2010). Kretzmann, McKnight, Sheehan, Green and Puntenney (1997:1) emphasise the importance of coping being embedded in the community, by stating that 'communities are made stronger when residents use their full potential by directing their capacities toward the well-being of the neighbourhood'. Community-based coping further supports the ubunt $u^{1}$ principle - a philosophy characteristic of South African indigenous communities, but one that seems to also be shaken in its foundations in the face of the ongoing misery and dwindling resources of especially poor, rural people.

Typical community-based responses to the HIV/AIDS pandemic range from informal care for orphaned children by relatives and neighbours; to planned intervention by outside organisations, who facilitate change within communities by involving community members (Cabassi 2004). Yet there are now so many orphans who head households that this communal way of caring is also facing enormous challenges (Statistics South Africa 2004; UNAIDS 2008).

The notion of 'community competence' may also eventually be abandoned, if measures are not put in place in schools, for example. These places are permanent and even if some teachers are also lost due to illness, for the immediate future teacher supply will be constant. External agencies might facilitate 
teacher professional development as lay community psychologists, which may help to alleviate very challenging trends. Within the context of the study reported on in this article, we employed such a selfhelp approach to community development (Bender 2004) and the promotion of mental health (Lazarus 2007; Naidoo, Duncan, Roos, Pillay \& Bowman 2007), involving teachers in a small intervention, based on our view that teachers are important agents and key role players in communities.

\section{Schools as community psychology hubs of action}

Besides other possible sources of support (such as extended family members or neighbours), a teacher can be a source of comfort for a child infected with or affected by HIV/AIDS. Kelly (2000) shows what a difference teacher attitudes and comfort make to children while at school. There is also now general agreement on the need to integrate HIV/AIDS education into the curriculum (Bennell, Chilisa, Hyde, Makgothi, Molobe \& Mpotokwane 2001; Kaira, Kohli \& Datta 2000). However, literature about specific plans of action and use of skills is still emergent.

It is also of concern to local community psychology scholars and practitioners that, despite the stipulation in the mentioned National Education Policy Act of 1996 (Department of Education 1999), the need for all schools to implement an HIV/AIDS plan, and the fact that 10000 teachers subsequently received training in the Life Skills programme, incorporating a continuing HIV/AIDS education programme, teachers in some areas know very little about the medical facts (Peltzer 2003). In addition, the Interagency Coalitions on AIDS and Development (ICAD 2001) state that HIV/AIDS training efforts have been held back by teachers due to their reluctance to discuss sexual issues, cultural resistance and the lack of adequate training on the topic. Hence, better training, information and preparation for teachers are essential. The participants in the study confirmed these needs by showing a willingness to fulfil a supporting (pastoral) role, yet they saw themselves as ill equipped to do so.

\section{Approaching school communities as human resources with social assets}

In the face of the dire circumstances referred to thus far, it would make no sense to plan an intervention in any other way, except by viewing the social strengths of role players as foundational to the work. Dunbar-Krige et al. (2010) argue for a 'recontextualisation' of community psychology, situating the school as the social 'communitas' and pursuing what strengths schools have as tools in the activity of supporting their community. For social upliftment, a realistic, asset-orientated approach to mental health care-giving is essential. In this project we thus undertook to work in such a way: we would thus focus on the existing strengths, knowledge and abilities of role players, emphasising their social agency (even though it was fast diminishing) (Ebersöhn \& Eloff 2006; Kretzmann \& McKnight 1996), believing that people hold within them (and within their environments) the strength and capabilities to solve problem situations and address the challenges they face (Lazarus 2007), even though the tensions between agency and structure are increasing.

Applying the asset-based approach to the challenge of coping with HIV/AIDS in contemporary South Africa, implies that the focus shifts from making inventories of the shortfalls of households and communities, to mobilising and putting to work the natural, cultural and physical resources, skills, abilities, networks and support systems - in short, the assets - that already exist and are locally available for everyday use. Instead of proposing a corrective approach, which essentially posits people infected with and affected by HIV/AIDS as victims in need of external intervention, we regard teachers and ground-level community members as agents and experts who hold the key to developing appropriate coping strategies within the community. As such, we view the role of the educational psychologist or registered counsellor as that of facilitator - not providing external help and assistance, but initiating a process during which teachers/community members themselves take ownership (Lazarus 2007; Naidoo 
et al. 2007). When we thus refer to the school as the 'hub' of community psychology, we mean that it is the communal social space whence actors as agents can pursue a goal and where they do not work alone, but can also rely on the support of co-workers.

In line with the basic principles of an asset-based approach, and according to the main tenets of community psychology (Society for Psychology in the American Psychological Association), pioneers in community capacity building propose that outsiders (such as the government, NGOs or other volunteers) should act as facilitators in guiding community members to identify the community's challenges, needs and strengths. They also formulate and implement plans and ways of utilising existing strengths to address identified challenges and improve conditions in a community (Kretzmann \& McKnight 1996; Langa 2007; Snow 2001). During our study we relied on these principles, developing an intervention that facilitated a process during which the participating teachers identified their existing knowledge and skills, thereby realising that they may have the answers within themselves. As such, the intervention we employed served as a catalyst that facilitated a process during which participants could experience feelings of competence to support their community in coping with HIV/AIDS (Langa 2007; Lazarus 2007; Mokwena 1997).

\section{Research methods}

We worked in a case study research design, partially applying participatory action research principles (PAR) (Bhana 2002; McMillan \& Schumacher 2000), with the 'bounded system' (Henning, Van Rensburg and Smit, 2004; Stake 2005) of the case being the intervention programme in an informal settlement community situated in the Eastern Cape Province of South Africa. According to Bhana (2002), citing literature from the PAR scholarly community, researchers rely on PAR in an attempt to generate knowledge in collaboration with the people involved in a study, with the secondary outcome being the participants' improved conditions on a variety of levels. PAR can be regarded as a community-based participatory approach, during which people who are directly affected by a certain phenomenon are encouraged to take action and contribute to their own wellbeing, rather than merely receiving assistance from outside agencies (Chambers 2004). By being involved and contributing to a research process, community members fulfil the role of active partners, resulting in their experiencing improved levels of ownership and taking action. As such, PAR supports the underlying principles of both an asset-based approach and of community psychology generally (American Psychological Association 2010.)

The participants were selected by means of convenience sampling, as they were already involved in the broader research project at the onset of our study, and therefore easily accessible (Mertens 1998). For the purpose of the broader research project (Ferreira 2006), the teachers were initially selected purposefully from a community where there is a known prevalence of HIV/AIDS (Merriam 1998; Patton 2002).

\section{Data sourcing}

The first phase involved an analysis of the transcripts of the broader research project (Ferreira 2006), whereby all the researchers in this larger project familiarised themselves with the perceived needs of teachers in terms of basic HIV/AIDS knowledge and skills. Building on this, we conducted semistructured interviews with four teachers. Besides the aim of confirming the results of our initial analysis of the transcripts, the purpose of the interviews was to explore the participants' (teachers') modes of support at the time, as well as their expectations regarding a proposed HIV/AIDS skills development workshop. All interviews were audio-recorded and transcribed verbatim, for the purpose of data analysis.

Our thematic analysis of the transcripts of the broader research project and the initial interviews provided us with baseline data that could be used to develop the intervention we planned. In this manner, 
the intervention was specifically developed to facilitate discussions among the participants regarding the skills and knowledge they needed. In addition to the transcripts of the four interviews, we thematically analysed our observations, which we documented in the form of field notes, while conducting the interviews (Mayan 2001; Patton 2002). We then relied on our analysis and interpretation of the data in planning the intervention, drawing on the strengths of the teachers, as identified in the data.

Phase two of the study took place during a second field visit, in which we facilitated the intervention with ten participants. The intervention took the form of a workshop, during which we facilitated a discussion that focused on the participants' existing competencies and coping skills, aiming to align these with their perceived shortcomings. During the intervention, we facilitated discussions on the following main topics identified by the participants during phase one of the study: 1) coping with children infected with or affected by HIV/AIDS in the classroom; 2) guidelines on the referral of community members infected with and affected by HIV/AIDS; and 3) ways of supporting vulnerable community members, including orphaned children.

In addition, as part of phase two of the study, we facilitated a focus-group discussion after the intervention had been completed (Berg 1998; McMillan \& Schumacher 2000), exploring participants' perceptions in terms of the degree to which their expectations had been met regarding their initial thoughts on required training. We also asked them how they had experienced the intervention. McMillan and Schumacher (2000) regard a focus-group discussion as suitable for obtaining such an understanding. For this phase, we again thematically analysed and interpreted the focus-group data, as well as observations and reflections which were recorded as field notes. In addition, we analysed visual material we obtained during the intervention, in the form of photographs and posters compiled by the participants (Mayan 2001; Patton 2002), aiming to find some discursive cues in the material.

\section{Phase One: Teachers' perceptions prior to the intervention}

Based on our initial data analysis during the first phase of the study, two main themes were identified, each comprising three sub-themes. Firstly, we identified a willingness among participants to offer support. Yet, secondly, they displayed feelings of inadequacy in offering such support. Though these findings are by no means unique or unexpected, the detail did assist us in re-thinking interventions like these. We realise that not even accomplished healthcare professionals feel confident in their knowledge, when working with people who deal with such challenges. Thus, lay practitioners, trained in a small way, may continue to feel inadequate and we surmise that it is a sense of 'communitas' in a school community that will see them through the rough times.

\section{Teachers' willingness}

Three sub-themes were identified and related to the urgency of the matter of helping. Firstly, the participants showed a sense of urgency to provide support: ' ... the problem is now. What can she use now? What they need now is what is important.' The participating teachers expressed their own sense of trauma: ' ... that is why it is a trauma even to us, but we are not going to cry, we must be bold, we must be strong for them, you see.'

The teachers took on the responsibility, highlighting that because teachers were trusted and looked up to, they were the ones to spread/teach the correct information on HIV/AIDS to community members: 'You know I want to teach them, maybe the community, the parents about the teaching of the community or of the families. I must know the priority topics.' Another participant highlighted the fact that some community members were illiterate, and that teachers had the responsibility to continuously inform them about HIV/AIDS-related issues: 
Besides the unemployment and poverty, they are not educated. So you speak of HIV and AIDS you have to explain what is it, how one can get it, how it cannot, all that stuff. But then the next day that thing is gone to most of them so you have to speak it again, it mustn't be a once-off thing, it must go on, it must continue, an ongoing process.

The participating teachers also showed a willingness to support the community and were more motivated to do so than at the onset of the study:

What can we do to help? If there's someone infected, how can that person be helped, at home, at school or at work? How can we help that person? ... you have to give them emotional support. You can give them spiritual support because then they can help into the trauma for the family and for themselves.

\section{Teachers' sense of inadequacy}

In terms of the theme relating to the participants' sense of inadequate knowledge, there were again three sub-themes. Firstly, the participants said they had been employing certain support initiatives at the onset of the study, despite their own uncertainty. For example, they said they were supporting community members on a spiritual level:

Because I use to bring her prayers there. Three or four women would go there and pray for her, as well as a practical level. Why don't you have a small garden so that you can plant things? That's good advice, because you know that she's going to plant vegetables.

Participants supported community members by providing medical, physiological information on HIV/ AIDS. They also guided community members to access support structures within the community, such as the local social worker.

In the interview data, it was evident that the participants had the ability to identify and utilise assets in order to support their community. Assets were identified on a tangible level: 'You see sometimes it's difficult to go and buy, they can plant veggies in the garden so that they can get a veg to improvise you know', within the media, 'The programmes on TV helped me a lot, the books. There was a book that the department gave us, the department distributed it to all teachers', as well as among themselves, ' ... but it's because some teachers have ideas that can help others, you need to talk like this, so to get information even from teachers, teachers know better than I know.'

In addition, participants indicated that they were relying on their own social skills in building relationships with parents, in order to support families and children. One participant said: 'It's through friends ... when we are discussing the issue of HIV and find out what it is, then maybe you can say that has happened and that will help because you will find that people want to help but maybe some are shy to do so.'

However, the second sub-theme reflected their sense of inadequacy: 'Even us teachers we are not really sure what we know, you see. Sometimes we can even feel scared, you see.' This, in turn, seemed to obstruct their efforts when they felt they were not sure of something: 'The other one would bring a cheese and bread with cheese, but maybe the cheese is not good for her, but we want to help but we don't know what, if it is right or wrong.' As a result, during the initial interviews, participants said that a workshop of some kind could provide them with the confidence to elaborate on their support initiatives: 'Although I heard about them I need somebody who can give me surety, when we go to a workshop, this can help ... it will have a bit of more weight if someone is saying I got this at a teacher workshop.'

The third sub-theme relates to the teachers' need for practical supportive skills. Participants admitted that they, for example, did not know how to deal with HIV-infected children in the classroom. Some participants also referred to their own insecurities in terms of effective ways of maintaining confidentiality 
with regard to the HIV-positive status of a child, stating: 'We must help all the children but this is confidential a disease like this, but now that child is in the classroom and there are a lot of children that is next to her.' One of the participants voiced the possibility that teachers might have to change their classroom practices in order to accommodate an HIV-positive child: 'Now if they know that there's a child who is positive they must then change to be very kind to that child, because maybe that child will take that, and if you are shouting you will make the child even more sick.'

Furthermore, the participants expressed a need for more practical guidelines: 'Okay, now you've got sores, why don't you wear gloves or what can you do? The help that you can give her also means physical things that you can give her, not just talk.' In addition, they requested guidance on how to refer community members to relevant support structures: 'I want to know about the grant, about the social worker, how does that work?'

\section{Results of Phase Two: Outcome of the intervention}

Based on the analysis of our observations and field notes during the intervention, the visual data we collected, and the transcripts of the focus group we facilitated, the outcome of the asset-based intervention was, on the whole, quite positive. The participants' motivation to act as 'community psychology' lay practitioners had increased, along with their sense of adequacy.

The participants said they had gained confidence in their ability to support community members and felt more empowered: 'Before we were not sure if we are doing the right thing ... now we know we are on the right track', 'Now we are not afraid anymore, to assist anyone who come and disclose.'

The participants also showed a willingness to take ownership: 'Because I was in a mind that you people are going to tell us. But I found it out that we are actively involved. It is our thing now ...'

The comments furthermore told us that there may be a snowball effect: 'What I was thinking was that the question of HIV and AIDS was for social workers and nurses, not for us as teachers, but since you came here you have given us the assurance that we are also social workers and we are also nurses.' The snowball effect was mentioned within the context of the following systems: the wider community, 'As a result of you coming here, I have been involved in many things ... and now we can organise a parent meeting whereby the whole community is gonna be involved', the parent body of the school, 'I can now stand up and say to the parents this is right, this is not right', as well as other colleagues, 'You know what? We are going to help other teachers.'

The respondents felt more confident about their ability to transfer the knowledge they had gained during the intervention: 'We will tell others, then they should go and tell others, and not only at the school.' They also referred to the long-term goal of community: 'If you can teach that earlier, because these kids are going to be the community of the area, they are going to be the future generation of this area, then they will do better than the present generation.'

\section{Discussion and conclusion: The asset of 'care'}

The essence of the findings of this intervention research is that some knowledge and cohesion can add to lay practitioners' sense of self-efficacy. Community psychology as a field developed at times of great change and hardship (see Krige et al. 2010). Reliance on internal resources - one of them being the teachers' sense of care and compassion that was prevalent in all the data - is an important tenet of this field, and is documented in its scholarly domain (APA 2010; Trickett, as cited in Krige et al. 2010). This research has once more illustrated, although on a small scale, how some knowledge and a few skills may contribute to mental health in a school community. 
Our main argument in this article is thus that the notion of care as part of a teacher's espoused identity is a crucial component of projects like these. Noddings' (1984) work in this field is well known in education communities. Service learning (Petersen 2007), which is one aspect of it, is regarded as vital in community psychology circles (APA 2010), but more than anything a sense of community, as expressed by Turner (1982) and articulated recently by Hues and Morgan (2010) in this journal, is probably closer to what the school community psychology project is about. The sense of 'spiritual' togetherness in the face of great social challenges could be one of the strongest assets of local school communities - they live with HIV/AIDS, their suffering is mutual and their social action can be led by teachers such as those who are presented in this study.

Turner proposes that 'communitas' is a social sense that binds people together in often non-tangible ways, and can be a strong motivating factor for social action. We would argue that in PAR, such as the methodological position that framed this study, a sense of 'communitas' may be captured that will motivate teachers to fulfil their role as pastoral caregivers - especially in communities on the fringes of society. Especially children and youths who attend school in similar conditions to those in which this inquiry is set, require support from their teachers and their schools.

The call to train all teachers to support children, parents and community members is well documented. Bennell (2003) states that school management might promote a change in attitude for teachers to become more proactive in the identification, referral and monitoring of orphaned and vulnerable children, by means of appropriate teacher training. We would campaign for that. In support of this proposal, a study by Save the Children (2002) also advocates that teachers need to educate themselves on the effects HIV/ AIDS and poverty have on children, in an attempt to minimise discrimination in schools and the wider community. A study by Antle, Wells, Goldie, DeMatteo and King (2001) furthermore supports this idea, suggesting that schools and teachers (amongst other service providers) ought to be trained in terms of the potential effects of HIV/AIDS on families, advocating that schools need to be transformed into safe places where community members can disclose their status. We argue that the teachers in this study showed that with minimal intervention they can take small but confident steps to assist a community - a community which should include their pupils.

It was encouraging that the participants in this study and its larger antecedent were actively involved in generating knowledge and action plans such as those reported by Ebersöhn and Eloff (2006) and Kretzmann and McKnight (1996). The participants gained confidence and, more importantly, were alerted as to how 'care' plays out in compassionate practice.

\section{Note}

1 Emphasising the importance of community and collectivism.

\section{References}

American Psychology Association (APA). Available at: http://www.apa.org/ (Accessed on 15 August 2008). Antle, B.J., L.M. Wells, R.S. Goldie, D. DeMatteo and S.M. King. 2001. Challenges of parenting for families living with HIV\&AIDS. Social Work 46(2):159-169.

Bender, C.J.G. 2004. Community development. In Keys to educational psychology, ed. I. Eloff and L. Ebersöhn, 198-229. Cape Town: UCT Press.

Bennell, P. 2003. The impact of the AIDS epidemic on schooling in sub-Saharan Africa. Background paper for the Biennial Meeting of the Association for the Development of Education in Africa, December. 
Bennell, P., B. Chilisa, K. Hyde, A. Makgothi, E. Molobe and L. Mpotokwane. 2001. The impact of HIV/ AIDS on primary and secondary education in Botswana: Developing a comprehensive strategic response. United Kingdom: DFID Education Publication Dispatch.

Berg, B.L. 1998. Qualitative research methods for the social sciences. Boston: Allyn and Bacon.

Bhana, A. 2002. Participatory action research: A practical guide for realistic radicals. In Research in practice: Applied methods for the social sciences, eds. M. Terre Blanche and K. Durrheim, 227238. Cape Town: University of Cape Town Press.

Brookes, H., O. Shisana and L. Richter. 2004. The national household HIV prevalence and risk survey of South African children. Cape Town: HSRC Publishers.

Cabassi, J. 2004. Renewing our voice: Code of good practice for NGOs responding to HIVIAIDS. Geneva: NGO HIV/AIDS Code of Practice Project.

Chambers, R. 2004. Participatory workshops: A sourcebook of 21 sets of ideas and activities. London: Earthscan.

Connolly, C., M. Colvin, O. Shisana and D. Stoker. 2004. Epidemiology of HIV in South Africa - results of a national, community-based survey. South African Medical Journal 94(9):776-781.

Department of Education. 1999. Government Gazette, vol. 410, no. 20372, 10 August.

Department of Education. 2000. The HIV\&AIDS emergency - guidelines for educators. Pretoria: Department of Education.

Dunbar-Krige, H., J. Pillay and E. Henning. 2010. (Re-)positioning educational psychology in high-risk school communities. Education as Change 14(3):pagesthis issue

Ebersöhn, L. and L. Eloff. 2006. Life skills and assets. Pretoria: Van Schaik Publishers.

Ferreira, R. 2006. The relationship between coping with HIV\&AIDS and the asset-based approach. Unpublished PhD thesis, University of Pretoria.

Gow, J. and C. Desmond. 2002. The long-term socio-economic impact of HIV\&AIDS on children and the policy response in South Africa. Health Economics and HIV\&AIDS Research Division (HEARD). South Africa: University of Natal.

Henning, E., W. van Rensburg and B. Smit. 2004. Finding your way in qualitative research. Pretoria: Van Schaik.

Hues, H. and K. Morgan. 2010. The raising of the flag in 'Volkstaat' Orania: Perspectives on a school ceremony. Education as Change 14(1):33-46.

Interagency Coalition on AIDS and Development (ICAD). 2001. HIV/AIDS and Education. Ottawa: ICAD.

Kaira, R.M., A. Kohli and P. Datta. 2000. AIDS education in schools: An attempt towards integrating AIDS education with school curriculum. New Delhi: Vikas Publishing House.

Kelly, M.J. 2000. The impact of HIVIAIDS on the rights of the child to education. Lusaka: University of Zambia.

Kretzmann, J.P. and J.P. McKnight. 1996. Asset-based community development. National Civic Review 85(4):23-30.

Kretzmann, J.P., J.L. McKnight, G. Sheehan, M. Green and D. Puntenney. 1997. A guide to capacity inventories: Mobilizing the community skills of local residents. A community building workbook from the asset-based community development institute. Chicago: ACTA Publications.

Langa, M. 2007. Vulnerable communities: Former combatants in South Africa. In Community psychology: Analysis, context and action, eds. N. Duncan, B. Bowman, A. Naidoo, J. Pillay and V. Roos, 262-279. Cape Town: UCT Press.

Lazarus, S. 2007. Assumptions and values of community psychology. In Community psychology: Analysis, context and action, eds. N. Duncan, B. Bowman, A. Naidoo, J. Pillay and V. Roos, 67-83. Cape Town: UCT Press.

Lucas, S. 2004. Community, care, change, and hope: Local responses to HIV in Zambia. Washington, DC: Social \& Scientific Systems, Inc./The Synergy Project. 
Mallmann, S. 2002. Building resiliency among children affected by HIVIAIDS. Windhoek: Catholic AIDS Action.

Marais, H. 2005. Buckling: The impact of AIDS in South Africa 2005. Pretoria: Centre for the Study of AIDS, University of Pretoria.

Mayan, M.J. 2001. An introduction to qualitative methods: A training module for students and professionals. Edmonton: International Institute for Qualitative Methodology.

McMillan, J.H. and S. Schumacher. 2000. Research in education: A conceptual introduction. New York: Brooks Publications.

Merriam, S.B. 1998. Qualitative research and case study applications in education. San Francisco: John Willey \& Sons.

Mertens, D.M. 1998. Research methods in education and psychology: Integrating diversity with quantitative and qualitative approaches. California: Sage Publications.

Mokwena, K. 1997. Empowerment as a tool for community health development. CHASA Journal of Comprehensive Health 8(2):66-70.

Mugabe, M., M. Stirling and A. Whiteside. 2002. Future imperfect: Protecting children on the brink. Paper prepared for the Africa leadership consultation: Acting for children on the brink, 10 September, Johannesburg, South Africa.

Naidoo, A., N. Duncan, V. Roos, J. Pillay and B. Bowman. In Community psychology: Analysis, context and action, eds. N. Duncan, B. Bowman, A. Naidoo, J. Pillay and V. Roos, 9-23. Cape Town: UCT Press.

Nel, W., S. Lazarus and B. Daniels. 2010. Education support services policy and practice in South Africa: An example of community psychology in action? Education as Change 14(3):pages this issue

Noddings, N. 1984. Caring: A feminist approach to ethics and moral education. Berkeley: University of California Press.

Patton, M.Q. 2002. Qualitative research and evaluation methods. California: Sage Publications.

Peltzer, K. 2003. HIV/AIDS education in South Africa. Knowledge about HIV/AIDS: Educator attitude about and control of HIV/AIDS education. Social Behaviour \& Personality 31(4):349-359.

Petersen, N.F. 2007. Pre-service teacher education students' engagement with care and social justice in a service learning module. Education as Change 11(3) (Special issue: Community service learning):169-181.

Save the Children. 2002. The role of stigma and discrimination in increasing the vulnerability of children and youth infected with and affected by HIVIAIDS. Report on participatory workshops. United Kingdom: Save the Children.

Snow, L.K. 2001. The organization of hope: A workbook for rural asset-based community development. A community building workbook from the Asset-Based Community Development Institute. Chicago: ACTA Publications.

Stake, R. 2005. Qualitative case studies. In The Sage handbook of qualitative research, third edition, eds. N.K. Denzin and Y.S. Lincoln, 433-466. Thousand Oaks, CA: Sage.

Statistics South Africa. 2004. Mid-year population estimates, South Africa 2004. Pretoria: Statistics South Africa.

Townsend, L. and A. Dawes. 2004. Willingness to care for children orphaned by HIV/AIDS: A study of foster and adoptive parents. African Journal of AIDS Research 3(1):69-80.

Trickett, E.J. 1997. The interdependence of schools and communities: Developing an ecological mindset on school-community collaboration. In Applied ecological psychology for schools within communities: Assessment and intervention, eds. W. Martin and J. Swartz, 139-166. Mahwah, NJ: Lawrence Erlbaum.

Turner, V. 1982. From ritual to theatre: The human seriousness of play. New York: PAJ Publications. UNAIDS. 2002. A conceptual framework and basis for action: HIVIAIDS stigma and discrimination. Geneva: UNAIDS. 
UNAIDS. 2008. 2008 report on global AIDS epidemic. Geneva: UNAIDS.

UNAIDS/WHO. 2005. AIDS epidemic update, December 2005: Special report on HIV prevention. Geneva: UNAIDS.

Van Dyk, A.C. 2001. HIV/AIDS care and counselling: A multidisciplinary approach. Cape Town: Pearson Education South Africa.

Van Heerden, E. 2009. Liminality, transformation and communitas - Afrikaans identity as viewed through the lens of South African arts festivals: 1995-2006. PhD thesis, Stellenbosch University.

\section{Corresponding author}

Ronél Ferreira

University of Pretoria

Pretoria 0002

South Africa

E-mail: ronel.ferreira@up.ac.za

\section{Co-authors}

Liesel Ebersöhn: liesel.ebersohn@up.ac.za

Viona Odendaal: vionaodendaal@gmail.com 